\title{
Three-dimensional echocardiography for the assessment of left ventricular geometry and papillary muscle morphology in hypertrophic cardiomyopathy
}

\author{
Mustafa Erden ${ }^{1} \cdot$ Hannah G. van Velzen ${ }^{1}$ Myrthe E. Menting ${ }^{1} \cdot$ Annemien E. van den Bosch ${ }^{1}$ - Ben Ren ${ }^{1}$. \\ Michelle Michels ${ }^{1} \cdot$ Wim B. Vletter $^{1} \cdot$ Ron T. van Domburg $^{1} \cdot$ Arend F.L. Schinkel $^{1,2}$ (D)
}

Received: 3 August 2017 / Accepted: 21 November 2017 / Published online: 6 January 2018

(c) The Author(s) 2018. This article is an open access publication

\begin{abstract}
Background Hypertrophic cardiomyopathy (HC) is characterized by left ventricular (LV) hypertrophy and associated with papillary muscle (PM) abnormalities. The aim of this study was to evaluate the utility of three-dimensional echocardiography (3DE) for the geometric assessment of LV hypertrophy and PM morphology.

Methods The study included 24 patients with an established diagnosis of $\mathrm{HC}$ and 31 healthy controls. 3DE was performed using an iE33 or EPIQ 7C ultrasound system with an X5-1 transducer. QLAB software was used for the 3D analysis of LV wall thickness (LVWT) and PM morphology and hypertrophy; the number and cross-sectional area (CSA) of anterolateral and posteromedial PMs; and the presence of bifid or accessory PMs.

Results Patients with HC had a larger LVWT compared to controls in all segments $(p<0.001)$, and LVWT was largest in the midventricular septal segment $(2.12 \pm 0.68 \mathrm{~cm})$. The maximum LVWT followed a spiral pattern from the LV base to the apex. The CSA of both anterolateral and posteromedial PMs was larger in patients with HC than in controls (1.92 vs. 1.15 $\mathrm{cm}^{2} ; p=0.001$ and 1.46 vs. $1.08 \mathrm{~cm}^{2} ; p=0.033$, respectively). The CSA of the posteromedial PM was larger in patients with LVOT obstruction than in those without $\left(2.64 \mathrm{vs} 1.16 \mathrm{~cm}^{2}, p=0.021\right)$.

Conclusions 3DE allows the assessment of LV geometry and PM abnormalities in patients with HC. 3DE demonstrated that the maximum hypertrophy was variable and generally located in a spiral from the LV base to the apex.
\end{abstract}

Keywords Hypertrophic cardiomyopathy $\cdot 3 \mathrm{D}$ echocardiography $\cdot$ Papillary muscle

\section{Sommario}

Premessa La cardiomiopatia ipertrofica (HC) è caratterizzata da ipertrofia del ventricolo sinistro (LV) e associata ad anomalie del muscolo papillare (PM).

Scopo dello studio Lo scopo di questo lo studio è stato quello di valutare l'utilità dell'ecocardiografia tridimensionale (3DE) nell'ottenere una valutazione geometrica dell'ipertrofia del VS e della morfologia del PM.

Metodi Lo studio ha incluso 24 pazienti con diagnosi accertata di HC e 31 controlli sani. La 3DE è stata eseguita utilizzando un sistema ecografico iE33 o EPIQ 7C con un trasduttore X5-1. Il software QLAB è stato utilizzato per l'analisi 3D dello spessore della parete del LV (LVWT) e della morfologia e ipertrofia del PM; il numero e l'area della sezione trasversale (CSA) del PM anterolaterale e posteromediale e definire la presenza di PM bifidi o accessori.

Risultati I pazienti con HC avevano una LVWT maggiore rispetto ai controlli in tutti i segmenti $(p<0,001)$ e LVWT era maggiore nel segmento del setto medio-ventricolare $(2,12 \pm 0,68 \mathrm{~cm})$. La LVWT massima seguiva uno schema a spirale dalla base LV all' apice. La CSA di entrambi i PM anterolaterali e posteromediali era maggiore nei pazienti con HC rispetto ai controlli ( 1,92 vs $1,15 \mathrm{~cm}^{2} ; p=0,001$ e 1,46 vs $1,08 \mathrm{~cm}^{2} ; p=0,033$ rispettivamente). La CSA del PM posteromediale era maggiore nei pazienti con ostruzione LVOT rispetto a quelli senza (2,64 vs $\left.1,16 \mathrm{~cm}^{2}, p=0,021\right)$.

Conclusioni La 3DE consente di valutare la geometria LV e le anomalie di PM in pazienti con HC. La 3DE ha dimostrato che l'ipertrofia massima era variabile e generalmente conformata a spirale dalla base del LV all'apice.

Extended author information available on the last page of the article 


\section{Introduction}

Hypertrophic cardiomyopathy (HC) is the most common inherited cardiac disease, with an estimated prevalence of 1 in 500 [1]. Hypertrophic cardiomyopathy is characterized by a broad clinical and morphological spectrum including left ventricular (LV) hypertrophy and abnormal LV papillary muscle (PM) morphology and thickness [2-7]. Currently, two-dimensional echocardiography (2DE) is the most frequently used imaging modality for the diagnosis and follow-up of patients with HC $[8,9]$. Clearly, 2DE has inherent limitations that may be overcome by three-dimensional echocardiography (3DE). There are indications that 3DE allows a better geometric assessment of PM morphology and LV hypertrophy and may provide information that alters clinical decision making $[9,10]$. The aim of this study was to assess the utility of $3 \mathrm{DE}$ for the assessment of LV geometry and PM abnormalities in patients with $\mathrm{HC}$ as compared to healthy controls. Additionally, the relation between PM abnormalities and left ventricular outflow tract (LVOT) obstruction was studied.

\section{Methods}

\section{Patient population and study protocol}

This study included 24 consecutive patients with an established diagnosis of $\mathrm{HC}$ and 31 age-matched healthy controls. All patients underwent standard 2DE in conjunction with 3DE. Only patients with sufficient image quality were included in this study. The diagnosis of $\mathrm{HC}$ was based on a LV wall thickness (LVWT) $\geq 15 \mathrm{~mm}$ that was not explained by loading conditions. LVOT obstruction was defined as a resting or provocable gradient $\geq 30 \mathrm{mmHg}$ assessed by Doppler echocardiography. Patients with HC linked to Noonan's syndrome, Fabry's disease, or congenital heart defects were excluded.

\section{Echocardiography}

3DE was performed using an iE33 or EPIQ 7C ultrasound system (Philips, Best, The Netherlands) with a X5-1t matrix-array transducer. Electrocardiographically gated full-volume datasets of the LV (built from four subvolumes) were acquired in the parasternal long axis and apical views during breath-hold. Care was taken to include the complete LV including the PM, and septum within the imaging volume throughout the acquisition by adjusting the lateral and elevation widths of the acquisition sector. Each full-volume dataset was digitally stored and exported to QLAB 3DQA software (Philips, Best, The Netherlands) for offline analysis.

The full-volume LV 3DE dataset was displayed as three orthogonal multiplanar reconstruction views. For the analysis of end-diastolic LVWT, a 16-segment model was used, according to EAE/ASE recommendations [11]. The short-axis end-diastolic frames that provided the best visualization of the endocardial and epicardial borders were selected. The LVWT was assessed at the center of each myocardial segment from the leading endocardial edge to the leading epicardial edge. The geometric pattern of LV hypertrophy was determined by the location and extent of hypertrophy at basal, midventricular and apical level. For the PM analysis, the anterolateral PM (ALPM) and posteromedial PM (PPM) were identified. Subsequently, morphology of the PMs was assessed: Individual PMs were assessed using long- and short-axis images on different levels to identify bifid, double bifid and accessory PMs. The cross-sectional area (CSA) of each PM was measured in the short-axis view at midventricular level, and total CSA was calculated for the ALPM and PPM.

\section{Statistical analyses}

Statistical analyses were performed using SPSS 21 (IBM, Armonk, New York). Continuous variables are reported as mean \pm standard deviation. Categorical variables are expressed as number (\%). Mann-Whitney $U$ test was used to compare the continuous variables and the Chi-square test was used to compare categorical variables. A $p$ value $<0.05$ was considered statistically significant.

\section{Results}

\section{Patient characteristics}

The clinical characteristics of patients with $\mathrm{HC}$ and controls are summarized in Table 1. The age of the patients with $\mathrm{HC}$ and controls was comparable $(35 \pm 14$ vs $33 \pm 7$ years, $p=0.173)$, and the patient group included significantly more men $(88 \%$ vs $42 \%, p<0.05)$.

\section{Echocardiographic findings}

Measurements of LVWT obtained from 3DE are presented in Table 2. Overall, LVWT in all 16 segments was larger in patients with $\mathrm{HC}$ than in controls $(p<0.001)$. The maximal LVWT in patients with $\mathrm{HC}$ at basal LV level was observed in the inferoseptal segments $(1.87 \pm 0.62 \mathrm{~cm})$ and anteroseptal segments $(1.87 \pm 0.38 \mathrm{~cm})$; at midventricular level in the anteroseptal segments $(2.18 \pm 0.67 \mathrm{~cm})$; and at apical level 
Table 1 Characteristics of patients with hypertrophic cardiomyopathy $(\mathrm{HC})$ and healthy controls

\begin{tabular}{lllr}
\hline Variable & $\begin{array}{l}\text { Patients with HC } \\
(n=24)\end{array}$ & Controls $(n=31)$ & $p$ value \\
\hline Age (years) & $35 \pm 14$ & $33 \pm 7$ & 0.173 \\
Men & $21(88 \%)$ & $13(42 \%)$ & $<0.05$ \\
BMI $\left(\mathrm{kg} / \mathrm{m}^{2}\right)$ & $23 \pm 5$ & $23 \pm 2$ & \\
BSA $\left(\mathrm{m}^{2}\right)$ & $1.83 \pm 0.32$ & 0 & \\
Angina & $3(13 \%)$ & 0 & \\
Dyspnea & $6(25 \%)$ & 0 & \\
NYHA class $\geq$ II & $6(25 \%)$ & 0 & \\
Palpitations & $6(25 \%)$ & 0 & \\
LVOT obstruction $(\geq 30 \mathrm{mmHg})$ & $6(25 \%)$ & - & \\
Pathogenic mutations & & - & \\
Myosin-binding protein C & $8(33 \%)$ & - & \\
Myosin heavy chain & $2(8 \%)$ & - & \\
Troponin I & $1(4 \%)$ & $1(4 \%)$ & \\
Mitochondrial DNA & & & \\
\hline
\end{tabular}

Data are presented as mean \pm standard deviation or number $(\%)$

BSA body surface area, LVOT left ventricular outflow tract, NYHA New York Heart Association functional class
Table 2 Left ventricular wall thickness (LVWT) assessed by threedimensional echocardiography (3DE)

\begin{tabular}{lcll}
\hline Variable & $\begin{array}{l}\text { Patients with } \\
\text { HC }(n=24)\end{array}$ & Controls $(n=31)$ & $p$ value \\
& & & \\
Basal level & & & \\
Anterior & $1.43 \pm 0.37$ & $0.84 \pm 0.12$ & $<0.001$ \\
Anteroseptal & $1.87 \pm 0.38$ & $0.86 \pm 0.21$ & $<0.001$ \\
Inferoseptal & $1.87 \pm 0.62$ & $0.85 \pm 0.16$ & $<0.001$ \\
Inferior & $1.41 \pm 0.49$ & $0.80 \pm 0.15$ & $<0.001$ \\
Inferolateral & $1.25 \pm 0.26$ & $0.76 \pm 0.15$ & $<0.001$ \\
Anterolateral & $1.25 \pm 0.31$ & $0.73 \pm 0.14$ & $<0.001$ \\
Midventricular level & & \\
Anterior & $1.54 \pm 0.36$ & $0.86 \pm 0.17$ & $<0.001$ \\
Anteroseptal & $2.18 \pm 0.67$ & $0.87 \pm 0.20$ & $<0.001$ \\
Inferoseptal & $2.17 \pm 0.73$ & $0.89 \pm 0.14$ & $<0.001$ \\
Inferior & $1.47 \pm 0.42$ & $0.85 \pm 0.16$ & $<0.001$ \\
Inferolateral & $1.53 \pm 0.51$ & $0.75 \pm 0.14$ & $<0.001$ \\
Anterolateral & $1.46 \pm 0.46$ & $0.73 \pm 0.15$ & $<0.001$ \\
Apical level & & & $<0.001$ \\
Anterior & $1.52 \pm 0.28$ & $1.03 \pm 0.43$ & $<0.001$ \\
Septal & $1.69 \pm 0.71$ & $1.01 \pm 0.23$ & $<0.001$ \\
Inferior & $1.49 \pm 0.45$ & $0.85 \pm 0.21$ & \\
Lateral & $1.76 \pm 0.55$ & $0.94 \pm 0.35$ & \\
\hline & & & \\
\hline
\end{tabular}

Data are presented as mean \pm standard deviation in centimeter $H C$ hypertrophic cardiomyopathy

in the lateral segment $(1.76 \pm 0.55 \mathrm{~cm})$. The segments with maximal hypertrophy formed a spiral pattern from the base to the apex of the LV.
Table 3 Papillary muscle (PM) evaluated by three-dimensional echocardiography (3DE)

\begin{tabular}{llll}
\hline Variable & $\begin{array}{l}\text { Patients with } \\
\text { HC }(n=24)\end{array}$ & Controls $(n=31)$ & $p$ value \\
\hline ALPM & & & \\
Number & $1.7 \pm 0.5$ & $1.5 \pm 0.6$ & 0.172 \\
CSA $\left(\mathrm{cm}^{2}\right)$ & $1.92 \pm 0.81$ & $1.15 \pm 0.47$ & 0.001 \\
Bifid appearance & $3(13 \%)$ & $2(6 \%)$ & 0.352 \\
PPM & & & \\
Number & $1.9 \pm 0.4$ & $2.1 \pm 0.4$ & 0.288 \\
CSA (cm $\left.{ }^{2}\right)$ & $1.46 \pm 0.62$ & $1.08 \pm 0.37$ & 0.031 \\
Bifid appearance & $3(13 \%)$ & $1(3 \%)$ & 0.144 \\
Accessory PM & $5(21 \%)$ & $3(10 \%)$ & 0.276 \\
\hline
\end{tabular}

Data are presented as mean \pm standard deviation or number (\%)

$A L P M$ anterolateral papillary muscle, $C S A$ cross-sectional area, $H C$ hypertrophic cardiomyopathy, $P M$ papillary muscle, $P P M$ posteromedial papillary muscle

Measurements of PMs obtained from 3DE are presented in Table 3. The total ALPM and total PPM CSA were significantly larger in patients with $\mathrm{HC}$ than in controls $\left(1.92 \pm 0.81\right.$ vs. $1.15 \pm 0.47 \mathrm{~cm}^{2} ; p=0.001$ and $1.46 \pm 0.62$ vs. $1.08 \pm 0.37 \mathrm{~cm}^{2} ; p=0.031$, respectively). Figure $1 \mathrm{dem}-$ onstrates an example of the 3DE analysis of the PM area. There was no significant difference in the number of ALPMs and PPMs between patients with $\mathrm{HC}$ and controls. Moreover, bifid and accessory PMs were not observed more frequently in patients with $\mathrm{HC}$ than in controls. Figure 2 shows an example of a patient with $\mathrm{HC}$ and a bifid PM, and Fig. 3 demonstrates an example of an accessory PM visualized by $3 \mathrm{DE}$. 
Fig. 1 3DE assessment of anterolateral papillary muscle (ALPM) cross-sectional area in a patient with HC. a Long-axis plane; b Short-axis plane; c Coronal plane; d Alternative real time 3D. ALPM anterolateral papillary muscle, $L V$ left ventricle, $R V$ right ventricle, $V S$ ventricular septum
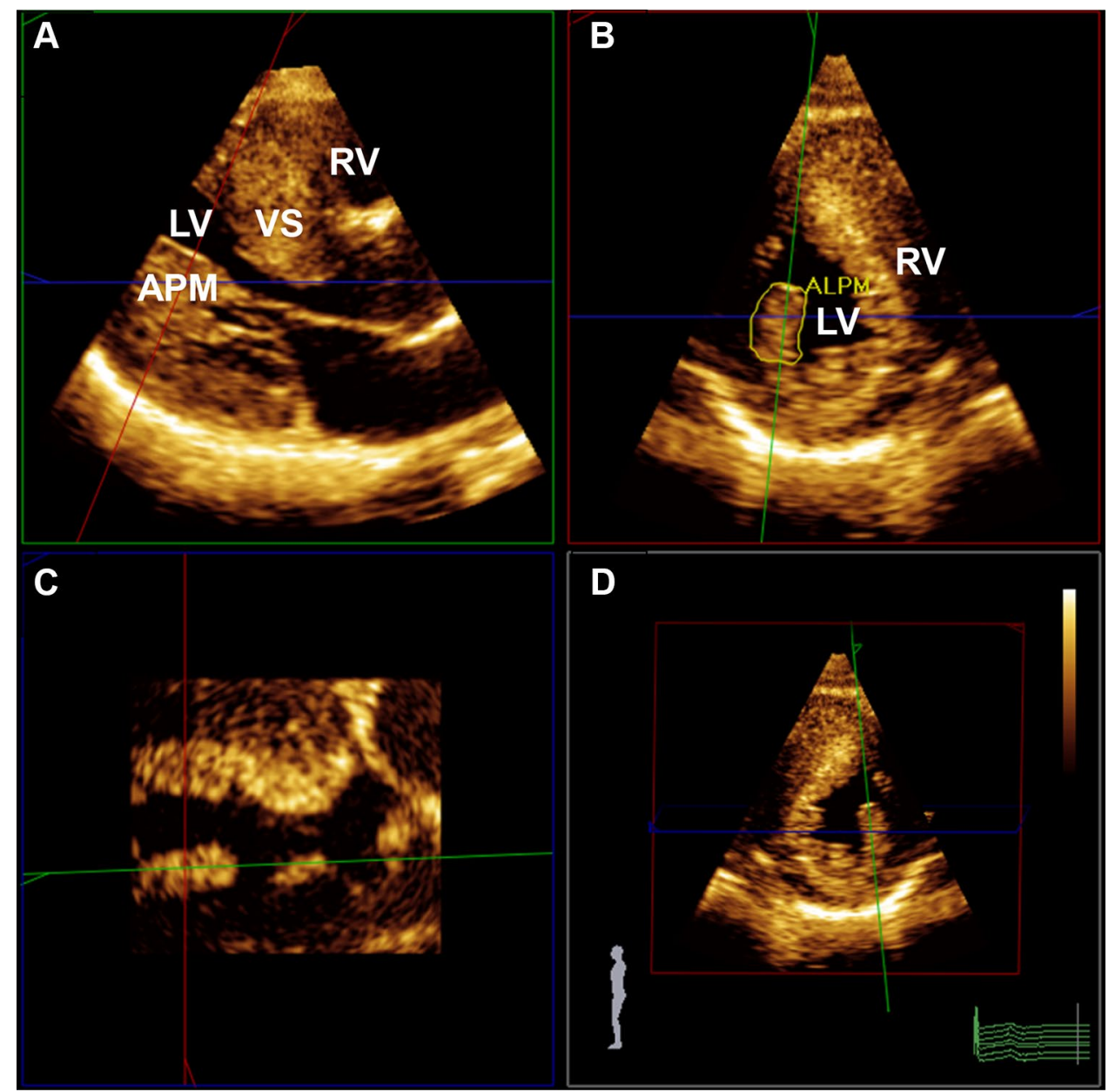

In the group of 24 patients with $\mathrm{HC}$, the median maximal LVOT gradient was 7 [IQR 4-30] mmHg. Six (25\%) patients with HC demonsutrated significant LVOT obstruction $(\geq 30 \mathrm{mmHg})$. The PPM CSA was larger in patients with LVOT obstruction than in patients without (median 2.64 vs $1.16 \mathrm{~cm}^{2} ; p=0.021$ ). The ALPM CSA was not different between patients with and without LVOT obstruction (2.00 vs $1.92 \mathrm{~cm}^{2}, p=0.88$ ).

\section{Discussion}

This study demonstrates the utility of 3DE for the assessment of the geometric pattern of LV hypertrophy and PM morphology in patients with HC. Maximal LV hypertrophy was present at basal level in the infero- and anteroseptal segments, at midventricular level in the anteroseptal segments, and at apical level in the lateral segments. The hypertrophy in patients with $\mathrm{HC}$ followed a spiral pattern from the LV base to the apex. 3DE allowed evaluation of the PM morphology and hypertrophy and showed that patients with HC had significantly hypertrophied PMs as compared to healthy controls. Moreover, the amount of hypertrophy of the PPM was related to significant LVOT obstruction.

Previous studies have demonstrated that 3DE may be superior to 2DE and has a comparable accuracy to that of CMR for determining LV volumes, mass, and ejection fraction in various patient groups [10, 12-14]. Shimada and Shiota [15] performed a meta-analysis of the accuracy of 3DE for the measurement of LV mass, including 18 articles with 25 studies. The meta-analysis showed that a significant improvement of the accuracy of the 3DE technique has been achieved over time. The improved accuracy in most recent studies on $3 \mathrm{DE}$ is probably related to an improvement in the temporal and spatial resolution of the probe, and a more developed data analysis method using updated software. The meta-analysis included two studies on the use of 3DE for the assessment of LV mass in patients with HC $[10,16]$. Oe et al. [16] studied the accuracy of 3DE in 21 patients with LV hypertrophy (17 with $\mathrm{HC}$, and 4 patients with hypertensive heart disease) using CMR as a reference technique. LV mass was estimated accurately and easily by 3DE, whereas LV mass assessed by 2DE correlated less well with CMR. Bicudo et al. [10] studied 20 patients with HC 
Fig. 2 3DE assessment of a bifid $\mathrm{PM}$ in a patient with $\mathrm{HC}$ (yellow arrows). a Long-axis plane, b Short-axis plane; c Coronal plane; d Real time 3D. $L V$ left ventricle, $M V$ mitral valve, $V S$ ventricular septum
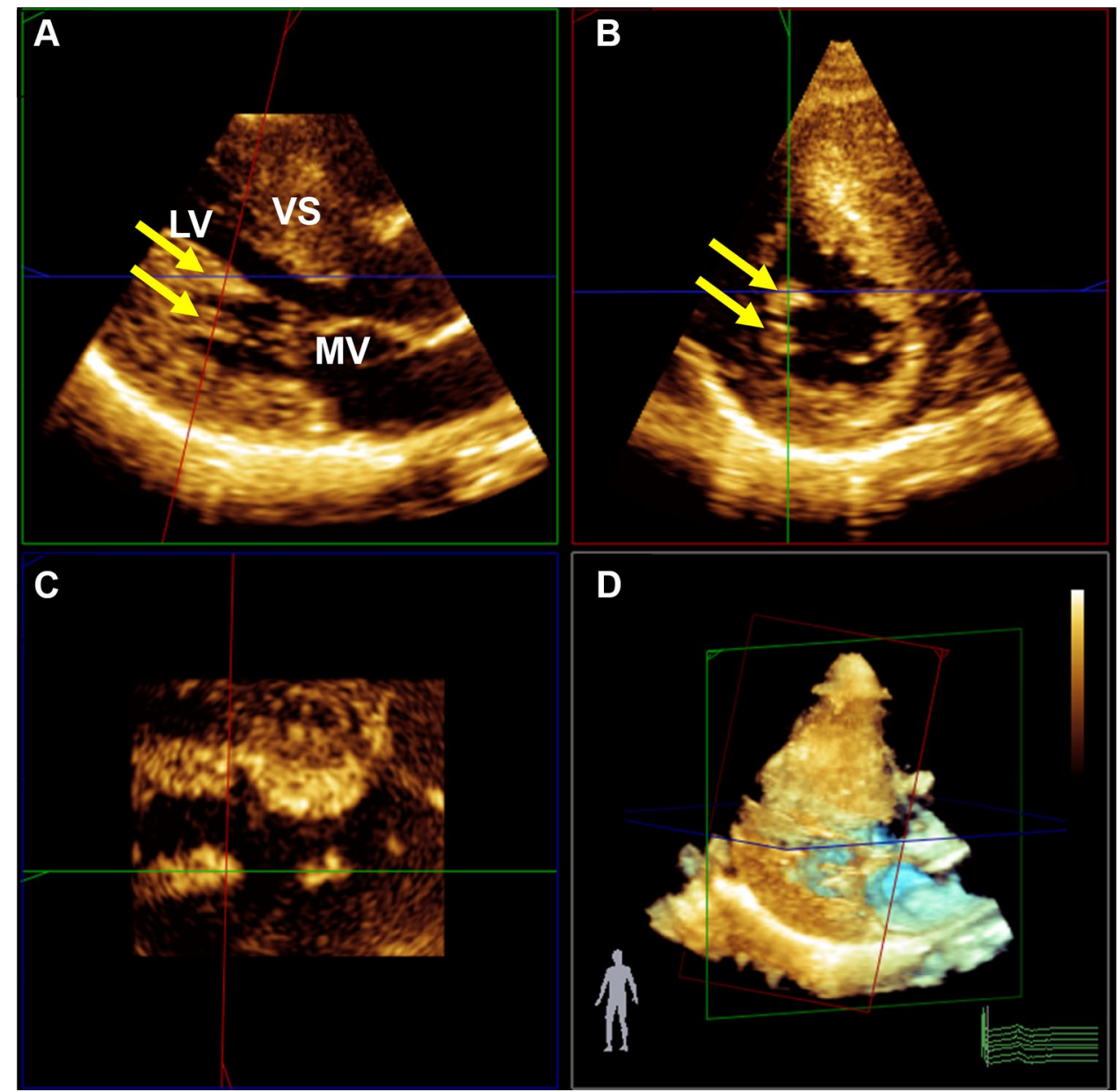

who underwent 2DE, 3DE and CMR. In that study, 3DE had a better performance than 2DE for the evaluation of LV hypertrophy, volumes, ejection fraction, and mass when compared to CMR. The current study extends the findings from these previous studies and demonstrates the utility of 3DE in patients with $\mathrm{HC}$ for the assessment of the geometric pattern of LV hypertrophy and PM morphology and hypertrophy. Hence, 3DE allows both the assessment of global LV hypertrophy (as measured by LV mass) as well as local hypertrophy (as measured by LV segmental wall thickness and PM CSA).

In this study, the amount and location of LV hypertrophy varied among patients with HC. Generally, a longitudinal spiral trajectory of the hypertrophy was observed. This is in line with a recent study by Florian et al. [17], who studied the geometry of hypertrophy on CMR in 132 patients with HC. Using 3D analysis, the majority of patients exhibited a spiral pattern of hypertrophy. As in the present study, the magnitude of hypertrophy and rotation was variable. This spiral distribution of the hypertrophy may be caused by predominant involvement of the subendocardial layers of the myocardium. These findings are in agreement with necropsy studies in patients who died from $\mathrm{HC}$, showing that the greatest cellular hypertrophy was in the layers closest to the cavity [18]. Likely, the distribution of hypertrophy is related to the stress distribution in the LV endocardium and subendocardium.

Approximately $30-60 \%$ of the patients with $\mathrm{HC}$ has a resting or provable LVOT obstruction, which may cause symptoms [19]. LVOT obstruction in patients with HC may be caused by several factors. Clearly, basal septal hypertrophy and systolic anterior movement of the mitral valve leaflet may cause LVOT obstruction. But also anatomical variations and hypertrophy of the PM may contribute [20]. Anatomical variations such as anterior displacement of the PM, the presence of a double bifid PM, anomalous insertion of the PM onto the anterior mitral valve leaflet, or fusion of the PM and the septum or LV free wall may have hemodynamic consequences.

Traditionally, 2DE has been used to assess the factors causing LVOT obstruction, but additional information may be obtained by $3 \mathrm{DE}$ and CMR. Our study demonstrates that the PPM CSA was larger in HC patients with LVOT obstruction than in those without. Previous studies have reported similar findings. Harrigan et al. [21] obtained CMR images in 201 patients with $\mathrm{HC}$ and 43 controls, in order to 
Fig. 3 3DE assessment of an accessory papillary muscle in a patient with $\mathrm{HC}$ (yellow and red arrows). a Long-axis plane; b Short-axis plane; c Coronal Plane; $\mathbf{d}$ Real time 3D. Ao ascending aorta, $L V$ left ventricle, $M V$ mitral valve, $R V$ right ventricle, $V S$ ventricular septum

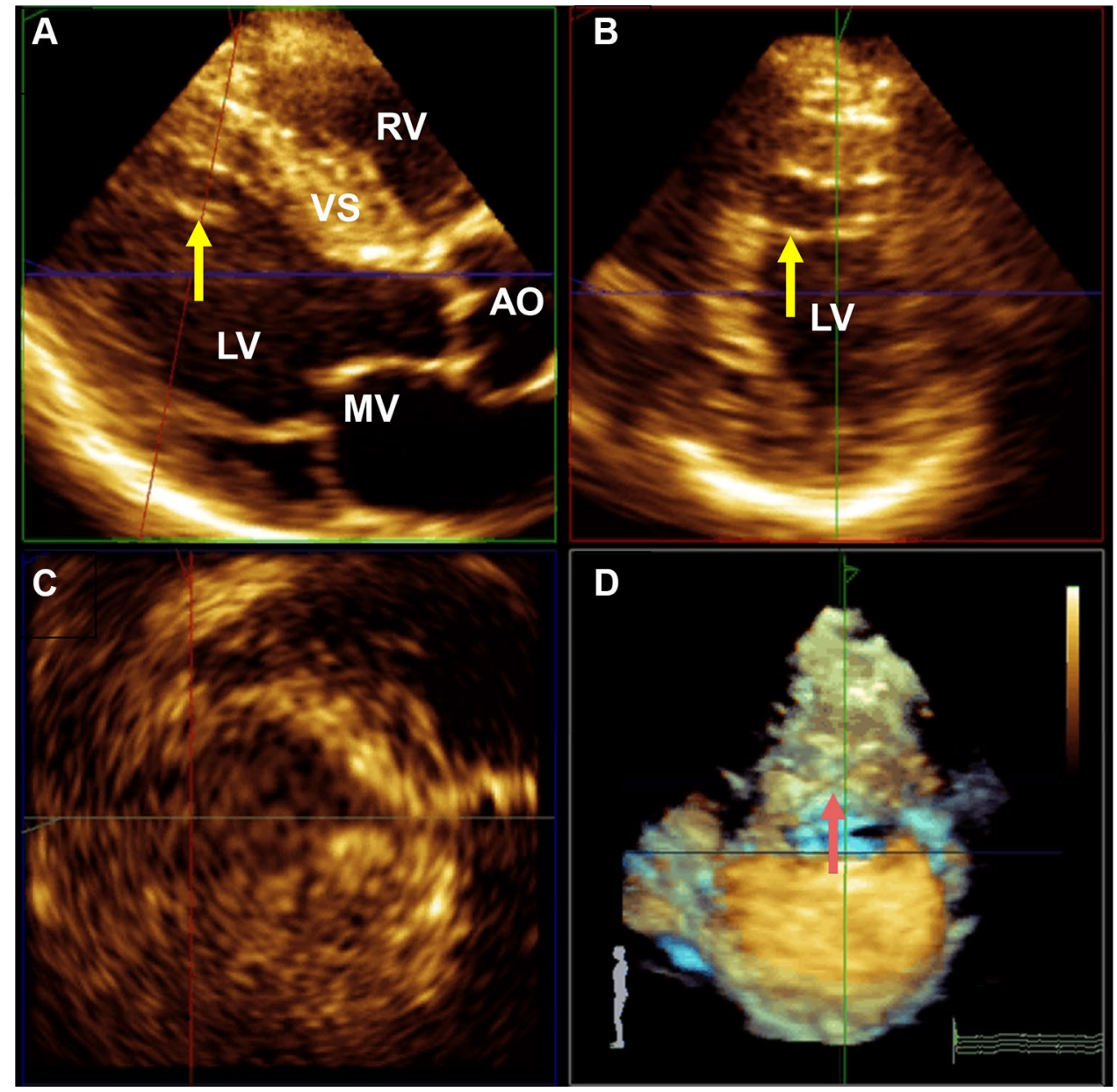

characterize PM morphology. PM mass index was significantly increased in patients with HC compared with controls, and PM hypertrophy was most severe in patients with LVOT obstruction. Furthermore, Kwon et al. [22] studied 56 patients with $\mathrm{HC}$ and 30 controls using CMR. The presence of PM abnormalities on CMR was correlated with resting LVOT gradients obtained by Doppler echocardiography. Patients with $\mathrm{HC}$ and abnormal PMs had significantly higher resting LVOT gradients, independent of septal LVWT. The identification of PM abnormalities may be relevant to understand the pathophysiology of LVOT obstruction and could have therapeutic consequences in patients with $\mathrm{HC}$ and significant LVOT obstruction who are considered for septal reduction surgery. Kwon et al. [23] have suggested that symptomatic patients with HC and significant LVOT obstruction with abnormal PM morphology may need surgical PM reorientation instead of or combined with standard surgical procedures. According to a large surgical series reported by Minakata et al. [6], patients with $\mathrm{HC}$ associated with anomalous PMs or chordae, including accessory PMs, can be successfully treated by surgical relief of morphological anomalies and an extended septal myectomy without mitral valve replacement. Finally, the utility of $3 \mathrm{DE}$ was also shown for the measurement of mitral leaflet surface area and subvalvular geometry in patients with HC. Kim et al. [24] studied 47 patients with $\mathrm{HC}$ and 32 controls using 3DE, and demonstrated that abnormal PM-mitral valve geometry assessed by 3DE may provide reasonable new targets for individualized surgical intervention.

This study has several limitations. First, the study population was relatively small, which may have affected the results. Second, only patients with sufficient image quality were included in the study. Third, the study was conducted in a referral center for patients with $\mathrm{HC}$ and may have therefore caused a bias. Fourth, the patient group included significantly more men than the control group. Finally, research is needed to integrate the findings from 3DE imaging in clinical decision making in order to improve outcome of patients with $\mathrm{HC}$.

In conclusion, 3DE allows the assessment of LV geometry and PM abnormalities in patients with HC. 3DE demonstrated that the maximum hypertrophy was variable and generally located in a spiral from the LV base to the apex. A better visualization of these structures may improve the understanding of the pathophysiology and may influence the surgical treatment of left ventricular outflow tract obstruction in these patients. 


\section{Compliance with ethical standards}

Conflict of interest The authors declare that they have no conflicts of interest.

Ethical approval Approval from the local ethics committee was obtained. The study was conducted according to the Declaration of Helsinki.

Informed consent All subjects consented participation in this study.

Open Access This article is distributed under the terms of the Creative Commons Attribution 4.0 International License (http://creativecomm ons.org/licenses/by/4.0/), which permits unrestricted use, distribution, and reproduction in any medium, provided you give appropriate credit to the original author(s) and the source, provide a link to the Creative Commons license, and indicate if changes were made.

\section{References}

1. Maron BJ, Gardin JM, Flack JM, Gidding SS, Kurosaki TT, Bild DE (1995) Prevalence of hypertrophic cardiomyopathy in a general population of young adults. Echocardiographic analysis of 4111 subjects in the CARDIA Study. Coronary artery risk development in (young) adults. Circulation 92:785-789

2. Klues HG, Maron BJ, Dollar AL, Roberts WC (1992) Diversity of structural mitral valve alterations in hypertrophic cardiomyopathy. Circulation 85:1651-1660

3. Niimura H, Patton KK, McKenna WJ, Soults J, Maron BJ, Seidman JG et al (2002) Sarcomere protein gene mutations in hypertrophic cardiomyopathy of the elderly. Circulation 105:446-451

4. Wigle ED, Sasson Z, Henderson MA, Ruddy TD, Fulop J, Rakowski H et al (1985) Hypertrophic cardiomyopathy. The importance of the site and the extent of hypertrophy. A review. Prog Cardiovasc Dis 28:1-83

5. Morita H, Larson MG, Barr SC, Vasan RS, O'Donnell CJ, Hirschhorn JN et al (2006) Single-gene mutations and increased left ventricular wall thickness in the community: the Framingham heart study. Circulation 113:2697-2705

6. Minakata K, Dearani JA, Nishimura RA, Maron BJ, Danielson GK (2004) Extended septal myectomy for hypertrophic obstructive cardiomyopathy with anomalous mitral papillary muscles or chordae. J Thorac Cardiovasc Surg 127:481-489

7. Klues HG, Roberts WC, Maron BJ (1991) Anomalous insertion of papillary-muscle directly into anterior mitral leaflet in hypertrophic cardiomyopathy-significance in producing left-ventricular outflow obstruction. Circulation 84:1188-1197

8. Afonso LC, Bernal J, Bax JJ, Abraham TP (2008) Echocardiography in hypertrophic cardiomyopathy the role of conventional and emerging technologies. Jacc-Cardiovasc Imag 1:787-800

9. Yang HS, Lee KS, Chaliki HP, Tazelaar HD, Lusk JL, Chandrasekaran $\mathrm{K}$ et al (2008) Anomalous insertion of the papillary muscle causing left ventricular outflow obstruction: visualization by real-time three-dimensional echocardiography. Eur J Echocardiogr. 9:855-860

10. Bicudo LS, Tsutsui JM, Shiozaki A, Rochitte CE, Arteaga E, Mady C et al (2008) Value of real time three-dimensional echocardiography in patients with hypertrophic cardiomyopathy: comparison with two-dimensional echocardiography and magnetic resonance imaging. Echocardiography 25:717-726
11. Lang RM, Badano LP, Tsang W, Adams DH, Agricola E, Buck T, American Society of E, European Association of E et al (2012) EAE/ASE recommendations for image acquisition and display using three-dimensional echocardiography. Eur Heart J Cardiovasc Imaging 13:1-46

12. Qi X, Cogar B, Hsiung MC, Nanda NC, Miller AP, Yelamanchili P et al (2007) Live/real time three-dimensional transthoracic echocardiographic assessment of left ventricular volumes, ejection fraction, and mass compared with magnetic resonance imaging. Echocardiography 24:166-173

13. Soliman OI, Krenning BJ, Geleijnse ML, Nemes A, van Geuns RJ, Baks $T$ et al (2007) A comparison between QLAB and TomTec full volume reconstruction for real time three-dimensional echocardiographic quantification of left ventricular volumes. Echocardiography 24:967-974

14. Gutierrez-Chico JL, Zamorano JL, Perez de Isla L, Orejas M, Almeria C, Rodrigo JL et al (2005) Comparison of left ventricular volumes and ejection fractions measured by three-dimensional echocardiography versus by two-dimensional echocardiography and cardiac magnetic resonance in patients with various cardiomyopathies. Am J Cardiol 95:809-813

15. Shimada YJ, Shiota T (2012) Meta-analysis of accuracy of left ventricular mass measurement by three-dimensional echocardiography. Am J Cardiol 110:445-452

16. Oe H, Hozumi T, Arai K, Matsumura Y, Negishi K, Sugioka K et al (2005) Comparison of accurate measurement of left ventricular mass in patients with hypertrophied hearts by real-time three-dimensional echocardiography versus magnetic resonance imaging. Am J Cardiol 95:1263-1267

17. Florian A, Masci PG, De Buck S, Aquaro GD, Claus P, Todiere G et al (2012) Geometric assessment of asymmetric septal hypertrophic cardiomyopathy by CMR. JACC Cardiovasc Imaging 5:702-711

18. Unverferth DV, Baker PB, Pearce LI, Lautman J, Roberts WC (1987) Regional myocyte hypertrophy and increased interstitial myocardial fibrosis in hypertrophic cardiomyopathy. Am J Cardiol 59:932-936

19. Maron MS, Olivotto I, Zenovich AG, Link MS, Pandian NG, Kuvin JT et al (2006) Hypertrophic cardiomyopathy is predominantly a disease of left ventricular outflow tract obstruction. Circulation 114:2232-2239

20. Teo EP, Teoh JG, Hung J (2015) Mitral valve and papillary muscle abnormalities in hypertrophic obstructive cardiomyopathy. Curr Opin Cardiol 30:475-482

21. Harrigan CJ, Appelbaum E, Maron BJ, Buros JL, Gibson CM, Lesser JR et al (2008) Significance of papillary muscle abnormalities identified by cardiovascular magnetic resonance in hypertrophic cardiomyopathy. Am J Cardiol 101:668-673

22. Kwon DH, Setser RM, Thamilarasan M, Popovich Z, Smedira N, Schoenhagen $P$ et al (2007) Abnormal papillary muscle morphology is independently associated with increased left ventricular outflow tract obstruction in hypertrophic cardiomyopathy. J Am Coll Cardiol 49:161a

23. Kwon DH, Smedira NG, Thamilarasan M, Lytle BW, Lever H, Desai MY (2010) Characteristics and surgical outcomes of symptomatic patients with hypertrophic cardiomyopathy with abnormal papillary muscle morphology undergoing papillary muscle reorientation. J Thorac Cardiovasc Surg 140:317-324

24. Kim DH, Handschumacher MD, Levine RA, Choi YS, Kim YJ, Yun SC et al (2010) In vivo measurement of mitral leaflet surface area and subvalvular geometry in patients with asymmetrical septal hypertrophy insights into the mechanism of outflow tract obstruction. Circulation 122:1298-1307 


\section{Affiliations}

Mustafa Erden ${ }^{1} \cdot$ Hannah G. van Velzen ${ }^{1} \cdot$ Myrthe E. Menting ${ }^{1} \cdot$ Annemien E. van den Bosch ${ }^{1} \cdot$ Ben Ren ${ }^{1}$. Michelle Michels ${ }^{1} \cdot$ Wim B. Vletter $^{1} \cdot$ Ron T. van Domburg ${ }^{1} \cdot$ Arend F.L. Schinkel $^{1,2} \mathbb{C}$

$\triangle$ Arend F.L. Schinkel a.schinkel@erasmusmc.nl

1 Department of Cardiology, Thoraxcenter, Erasmus Medical Center, Rotterdam, The Netherlands
2 Department of Cardiology, Erasmus MC, Thoraxcenter Room Ba304, 's-Gravendijkwal 230, 3015 Rotterdam, The Netherlands 